\title{
Ovarian Abnormalities in the Staggerer Mutant Mouse
}

\author{
Jean-Marie Guastavino ${ }^{1,2}$, Salima Boufares ${ }^{1}$, and Wim E. Crusio ${ }^{3, \star}$ \\ ${ }^{1}$ Laboratoire d'Ethologie et de Sociobiologie, Université de Paris XIII, Paris, France; \\ ${ }^{2}$ Present address: Service des Relations Internationales, Université Henri Poincaré- \\ Nancy I, 24-30 rue Lionnois, BP 60120, 54003 Nancy Cedex, France; ${ }^{3}$ Laboratoire \\ de Neurosciences Cognitives, CNRS UMR 5106, Avenue des Facultés, 33405 \\ Talence, France \\ E-mail:wim_crusio@yahoo.com
}

Received June 2, 2005; Revised August 14, 2005; Accepted August 16, 2005; Published August 24, 2005

Disturbances in several reproductive functions of the staggerer cerebellar mutant mouse have been observed. In this study, reproductive efficiency of staggerer mice was compared to normal mice by recording the number of pups produced and the number of oocytes occurring. It was found that staggerer mothers produced smaller litters than controls and the number of oocytes produced in their ovaries was reduced by the staggerer mutation. These results indicate a pleiotropic effect on fertility of the Rora ${ }^{s g}$ gene underlying the cerebellar abnormalities of the staggerer mutant.

KEYWORDS: staggerer, ovary, cerebellum, reproduction, fertility, neurological mutant

\section{INTRODUCTION}

The target of the staggerer mutation was first described as a cerebellar atrophy resulting in alteration of gait and body balance[1,2]. The staggerer mutation (original gene symbol sg, now Rora ${ }^{\text {sg }}$; chromosome 9) is a deletion in the gene coding for the retinoic acid-related orphan receptor alpha (ROR $\alpha$ ), a member of the nuclear hormone-receptor superfamily[3]. In normal mice, this receptor interacts with the thyroid pathway to regulate the development of Purkinje cells[3]. Indeed, the observed motor deficits seem to be primarily due to a defect in the early postnatal development of the Purkinje cells[4]. Other research has indicated several other anatomical and functional abnormalities including alterations of the immune system[5,6,7], reactions to novelty[8,9,10,11], spatial learning[12,13,14], cold adaptation[15,16], olfactory bulb characteristics[17,18], and reproductive behavior[19,20]. Reproduction is often altered in mutants and this appears also to be the case for the staggerer mutation, where both male and female reproductive capacity are highly abnormal[20,21,22]: Few staggerer males were sexually active, often showing a constant penile erection[22]. Over a 15-year period of breeding in our laboratory, we have found that about 2 out of 3 staggerer females reproduce. Nevertheless, although able to reproduce, staggerer females showed delayed onset of puberty, abnormalities in the estrous cycle[23], and a marked acceleration of the reproductive aging process[20]. The abnormal temporal pattern of the female 
reproductive functions prompted us to investigate systematically the fertility of the staggerer female by the number of pups produced and by the number of oocytes present in the ovaries.

\section{METHODS}

The animals used in this study were mutant and nonmutant female mice on a congenic C57BL/6J background, bred in our laboratory since 1980. Mutants were $\operatorname{Rora}^{\mathrm{sg}} / \mathrm{Rora}^{\mathrm{sg}}$ and were the offspring of intercrosses between $+/$ Rora $^{s g}$ heterozygotes. Since the mutation is recessive, and homozygous and heterozygous animals cannot be distinguished from one another phenotypically, the control group of nonmutants consisted of the $+/+$ or $+/$ Rora $^{\text {sg }}$ offspring of the same matings. The animals were housed in standard mouse cages with a 12:12 light-dark cycle with lights on at 9 a.m., $24^{\circ} \mathrm{C}$, and with free access to solid and soft food and water. The females were weaned at 35 days of age and thereafter maintained in groups of 6 females.

To compare the number of pups produced, we used 15 staggerer and 15 control females. A first crossing with normal males was performed when the animals were 2-4 months old. Later, when the animals were 4-6 months old, a second crossing was performed. For both crossings, the number of pups born was counted.

For the study of the ovaries, 8 primiparous staggerer and 8 control females were used. When the animals were 3.5-5 months old, and about 2-4 weeks after parturition, the ovaries were removed. Only one ovary per female was used. The ovarian tissues were fixed for $24 \mathrm{~h}$ in a solution of Bouin Holland and washed with water for at least 1 day to eliminate excess picric acid. Specimens were then dehydrated in a graded series of ethanol and finally washed in butanol. After embedding in paraffin, transverse 5- $\mu$ mthick sections were cut and mounted on slides.

The slices were colored by a Schiff periodic acid solution (1\%) for $10 \mathrm{~min}$, rinsed repeatedly before being treated with Schiff reagent, and thereafter rinsed again. The slices were thereafter treated with hematoxyline of Groat for $10 \mathrm{~min}$. After prolonged rinsing (15 min), the slices were subjected to a final dehydration procedure and mounted on glasses using a synthetic resin (Eukitt, Kindler, Freiburg, Germany) before being checked under the microscope (Reichert, Polyvar).

\section{RESULTS AND CONCLUSIONS}

As shown in Table l, the staggerer mothers produced significantly fewer pups per litter than the controls both after the first and the second mating. Also, the numbers of oocytes counted was significantly lower in the staggerer females than in the controls $(p<0.05)$. Comparing the number of pups between the first and second mating, a statistically significant increase was seen both in the staggerer females $(p<0.01)$ and in the controls $(p<0.01)$.

The present results show that reproductive function is one of the targets of the staggerer mutation as evidenced both by the number of pups produced and the number of oocytes per ovary. These observations are interesting in the light of several other indications of reproductive deficits in the staggerer mouse as mentioned in the Introduction. At this point, it is difficult to explain these deficits, although it is unlikely that they are a direct consequence of the cerebellar dysfunction in these animals. One possibility is that the reduced fertility could be due to a pleiotropic effect of the Rora ${ }^{s g}$ allele. Alternatively, this deficit could be due to secondary effects of other disorders produced by this gene. We previously reported the involvement of the cerebellum in the organization of food intake and digestive functions[16] and it is a well-established fact that undernutrition may be followed by alterations in reproductive functions. Further studies are needed to define the precise mechanisms involved in mediating the alterations. 
TABLE 1

The Number of Pups (mean \pm SEM) Produced After the

First and Second Matings of 15 Staggerer and 15 Normal Mice and Number of Oocytes Produced After the First Mating of 8 Staggerer and 8 Controls

\begin{tabular}{cccc}
\hline & Staggerer & Control & $\boldsymbol{p}^{*}$ \\
\hline \multicolumn{4}{c}{ Number of pups per litter } \\
Mating 1 & $6.76 \pm 0.41$ & $8.53 \pm 0.65$ & $<0.02$ \\
Mating 2 & $8.31 \pm 0.37$ & $10.40 \pm 0.68$ & $<0.01$ \\
& \multicolumn{3}{c}{ Number of oocytes per ovary } \\
& $5.25 \pm 0.37$ & $6.75 \pm 0.37$ & $<0.05$ \\
\hline
\end{tabular}

*Mann-Whitney U-Test[24]

\section{ACKNOWLEDGMENTS}

We thank the Centre National de la Recherche Scientifique (CNRS, Paris, France), the Swedish Natural Science Research Council (NFR, Stockholm, Sweden), and the Swedish-French Association for Research (ASFR, Stockholm, Sweden) for support.

\section{REFERENCES}

1. Sidman, R.L., Lane, P.W., and Dickie, M.M. (1962) Staggerer, a new mutation in the mouse affecting the cerebellum. Science 137, 610-612.

2. Sidman, R.L. (1968) Development of interneural connections in brains of mutant mice. In Physiological and Biochemical Aspects of Nervous Integration. Carlson, F.D., Ed. Prentice-Hall, Englewood Cliffs, NJ. pp. 163-193.

3. Hamilton, B.A., Frankel, W.N., Kerrebrock, A.W., Hawkins, T.L., FitzHugh, W., Kusumi, K., Russell, L.B., Mueller, K.L., vanBerkel, V., Birren, B.W., Kruglyak, L., and Lander, E.S. (1996) Disruption of the nuclear hormone receptor RORa in staggerer mice. Nature 379, 736-739.

4. Shirley, L.T. and Messer, A. (2004) Early postnatal Purkinje cells from staggerer mice undergo aberrant development in vitro with characteristic morphologic and gene expression abnormalities. Dev. Brain Res. 152, 153-157.

5. Trenkner, E. and Hoffmann, M.K. (1986) Defective development of the thymus and immunological abnormalities in the neurological mouse mutation "staggerer”. J. Neurosci. 6, 1733-1737.

6. Kopmels, B., Wollman, E.E., Guastavino, J.M., Delhaye-Bouchaud, N., Fradelizi, D., and Mariani, J. (1990) Interleukin-1 hyperproduction by in vitro activated peripheral macrophages from cerebellar mutant mice. $J$. Neurochem. 55, 1980-1985.

7. $\quad$ Kopmels, B., Mariani, J., Delhaye-Bouchaud, N., Audibert, F., Fradelizi, D., and Wollman, E.E. (1992) Evidence for a hyperexcitability state of staggerer mutant mice macrophages. J. Neurochem. 58, 192-199.

8. Misslin, R., Cigrang, M., and Guastavino, J.M. (1986) Responses to novelty in staggerer mutant mice. Behav. Process. 12, 51-56.

9. $\quad$ Lalonde, R. (1987) Exploration and spatial learning in staggerer mutant mice. J. Neurogenet. 4, $285-291$.

10. Lalonde, R., Botez, M.I., and Boivin, D. (1987) Object exploration in staggerer mutant mice. Physiol. Behav. 41, 115117.

11. Lalonde, R., Manseau, M., and Botez, M.I. (1988) Spontaneous alternation and exploration in staggerer mutant mice. Behav. Brain Res. 27, 273-276.

12. Lalonde, R., Filali, M., Bensoula, A.N., Monnier, C., and Guastavino, J.-M. (1996) Spatial learning in a Z-maze by cerebellar mutant mice. Physiol. Behav. 59, 83-86.

13. Bensoula, A.N., Guastavino, J.M., Lalonde, R., Portet, R., Bertin, R., and Krafft, B. (1995) Spatial navigation of staggerer and normal mice during juvenile and adult stages. Physiol. Behav. 58, 823-825.

14. Caston, J., Chianale, C., and Mariani, J. (2004) Spatial memory of heterozygous staggerer (Rora(+)/Rora(sg)) versus normal (Rora(+)/Rora(+)) mice during aging. Behav. Genet. 34, 319-324.

15. Guastavino, J.M., Bertin, R., and Portet, R. (1991) Effects of the rearing temperature on the temporal feeding pattern of the staggerer mutant mouse. Physiol. Behav. 49, 405-409. 
16. Bertin, R., Guastavino, J.M., and Portet, R. (1990) Effects of cold acclimation on the energetic metabolism of the staggerer mutant mouse. Physiol. Behav. 47, 377-380.

17. Michel, V., Monnier, Z., Guastavino, J.M., Propper, A., and Math, F. (2000) Functional alterations in the olfactory bulb of the staggerer mutant mouse. Neurosci. Lett. 280, 1-4.

18. Deiss, V., Dubois, M., Lalonde, R., and Strazielle, C. (2001) Cytochrome oxidase activity in the olfactory system of staggerer mutant mice. Brain Res. 910, 126-133.

19. Bulloch, K., Hamburger, R.N., and Loy, R. (1982) Nest-building behavior in two cerebellar mutant mice: staggerer and weaver. Behav. Neural Biol. 36, 94-97.

20. Guastavino, J.M. and Larsson, K. (1992) The staggerer gene curtails the reproductive life span of females. Behav. Genet. 22, 101-112.

21. Guastavino, J.M., Larsson, K., Allain, C., and Jaisson, P. (1993) Neonatal vestibular stimulation and mating in cerebellar mutants. Behav. Genet. 23, 265-269.

22. Guastavino, J.M., Larsson, K., and Jaisson, P. (1992) Neurological murine mutants as models for single-gene effects on behavior. In Techniques for the Genetic Analysis of Brain and Behavior: Focus on the Mouse. Vol. 8. Goldowitz, D., Wahlsten, D., and Wimer, R.E., Eds. Elsevier, Amsterdam. pp. 375-390.

23. Larsson, K., Guastavino, J.M., and Ly, A.K. (1986) Altered reproductive behaviour of the neurological mutant mouse staggerer. In Genetic Approaches to Behaviour. Médioni, J. and Vaysse, G., Eds. Privat, Toulouse. pp. 69-79.

24. Siegel, S. (1956) Nonparametric Statistics for the Behavioral Sciences. McGraw-Hill, New York.

This article should be referenced as follows:

Guastavino, J.-M., Boufares, S., and Crusio, W.E. (2005) Ovarian abnormalities in the staggerer mutant mouse. TheScientificWorldJOURNAL 5, 661-664.

\section{Handling Editor:}

Steve Brown, Principal Editor for Genes and Genomics — a domain of TheScientificWorldJOURNAL. 

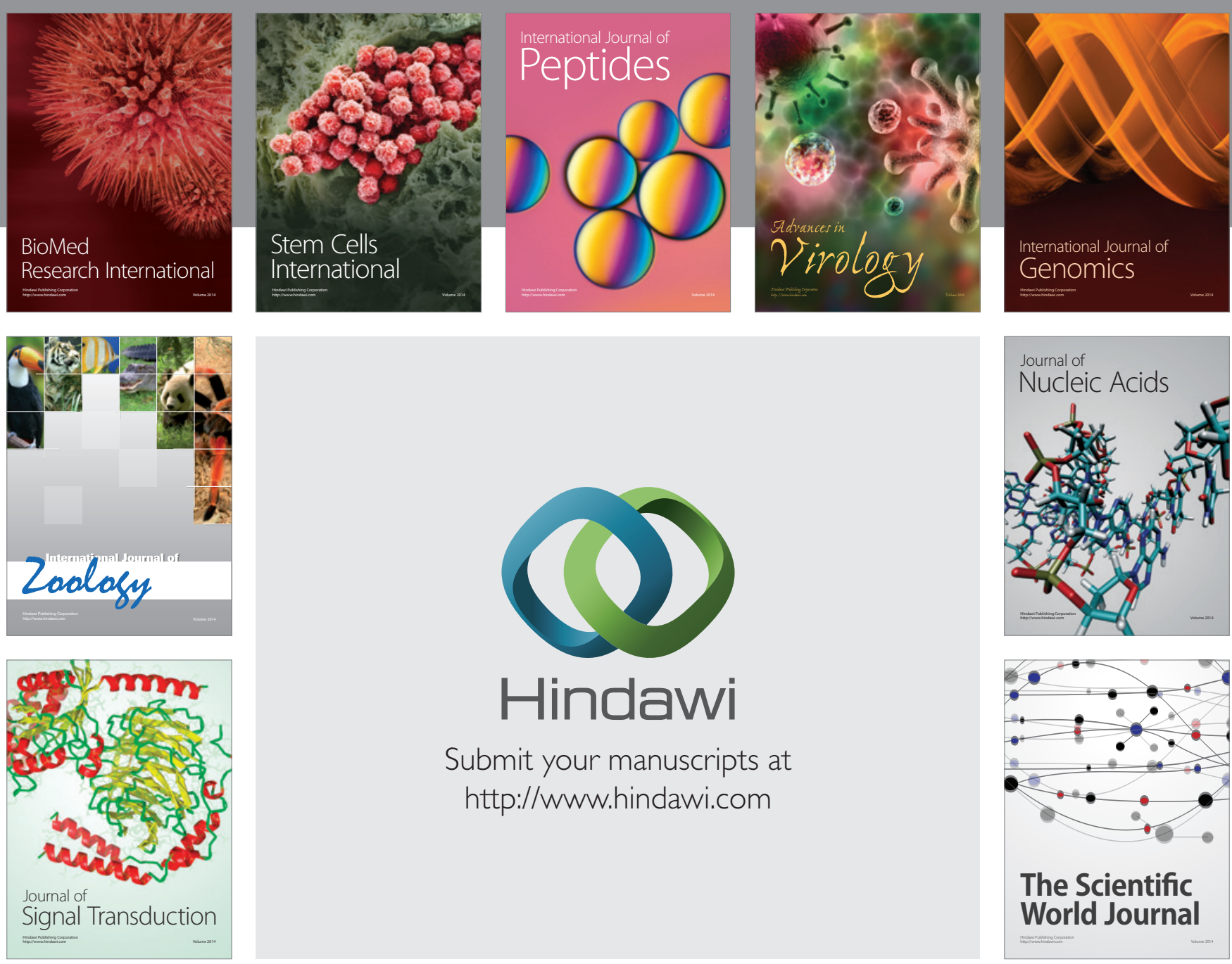

Submit your manuscripts at

http://www.hindawi.com
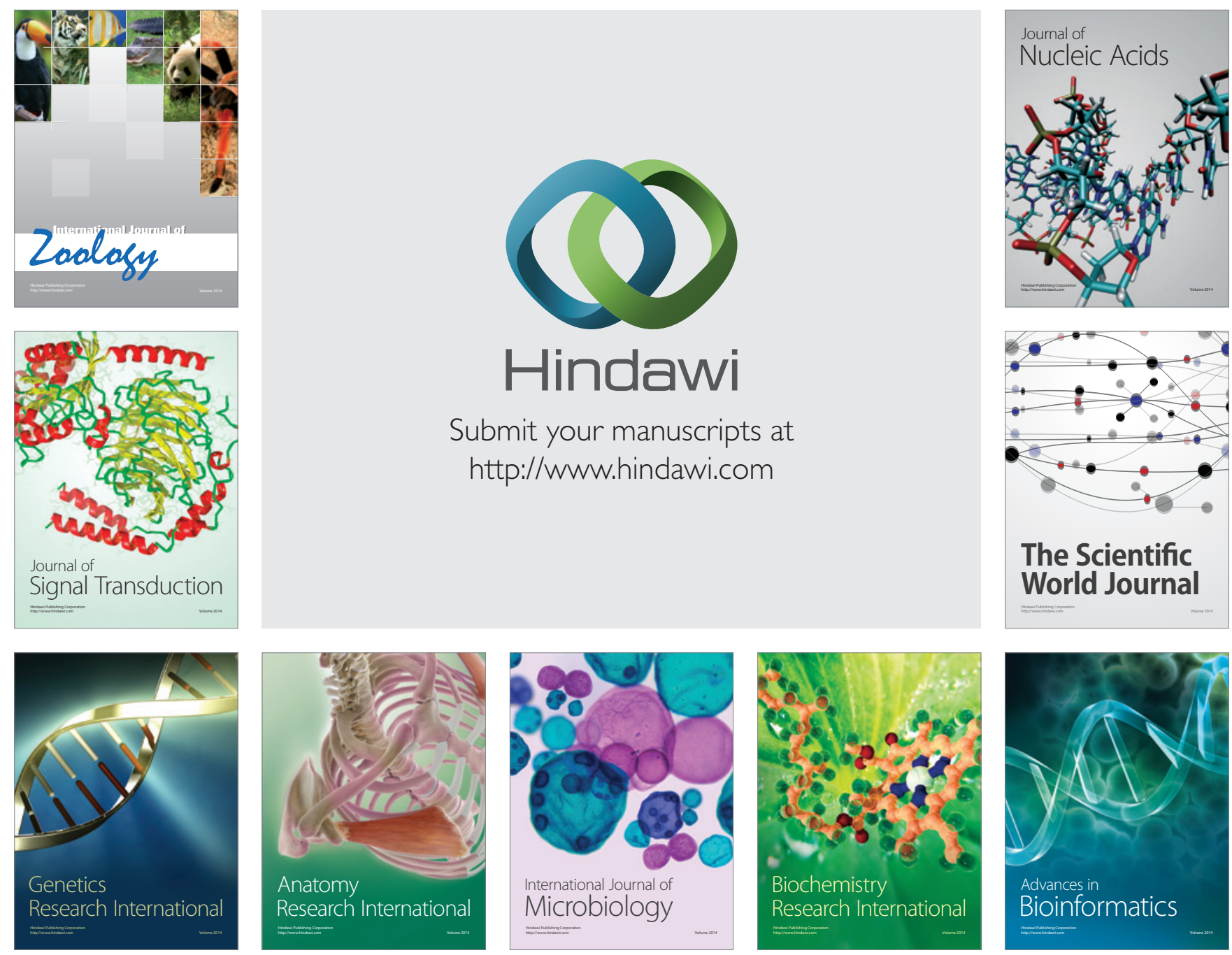

The Scientific World Journal
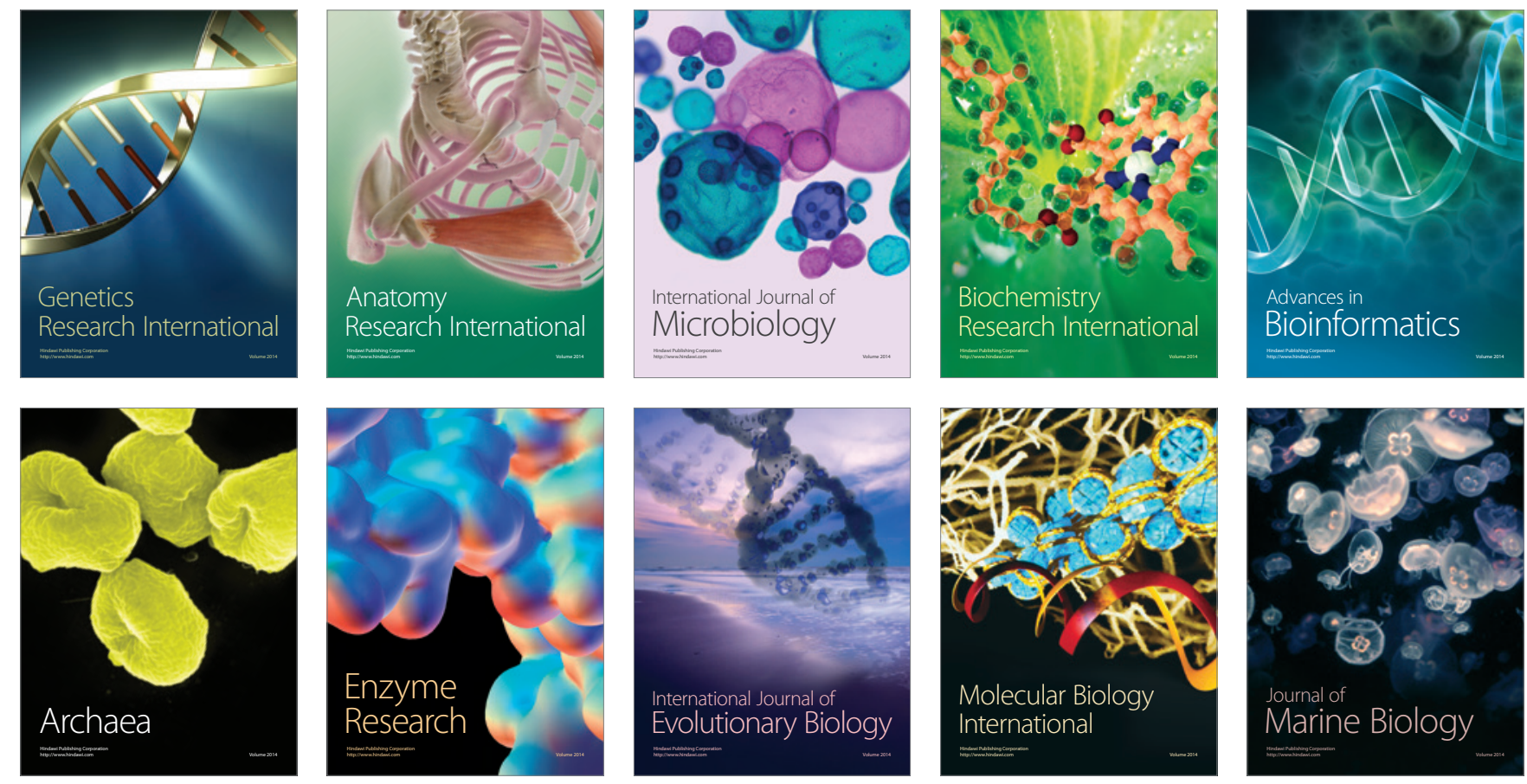